\title{
LA FUNCIÓN DE LA PENA EN EL ESTADO SOCIAL Y DEMOCRÁTICO DE DERECHO•
}

\author{
Lorenzo Morillas Cueva
}

lorenzom@ugr.es

Catedrático de Derecho Penal

Universidad de Granada (España)

RESUMEN: El núcleo esencial de esta exposición está basada fundamentalmente en dar respuestas a una pregunta esencial por multiforme para la comprensión de tan complejas, controvertidas y, veces, contradictorias instituciones en relación al ámbito social donde se ubican: ¿Cuál es la legitimación y función del Derecho penal y de la pena en una sociedad democrática?

Palabras clave: Pena, libertad, reinserción, garantía

ABSTRACT: The core of this exhibition is mainly based on providing answers to a crucial question for understanding such complex, controversial and sometimes contradictory institutions in relation to the social environment where they are located: What is the legitimacy and function criminal law and punishment in a democratic society?

Keywords: Freedom, reintegration, security

\footnotetext{
- El presente escrito corresponde a la parte científica de mi discurso en el acto de investidura de Doctor Honoris Causa por la Universidad de Almería (21 de marzo de 2013). Quiero reiterar en su publicación mi permanente agradecimiento a la Universidad de Almería por el alto honor que me ha concedido y que me llena de orgullo y satisfacción.
} 
I.

Sabido es que el artículo $1^{\circ}$ de la Constitución española proclama a nuestro país como un Estado social y democrático de Derecho, que propugna como valores superiores de su ordenamiento jurídico la libertad, la justicia, la igualdad y el pluralismo político. El artículo 25.2 en relación con las penas privativas de libertad y las medidas de seguridad marca que "estarán orientadas hacia la reeducación y reinserción social y no podrán consistir en trabajos forzados. El condenado a pena de prisión que estuviere cumpliendo la misma gozará de los derechos fundamentales de este Capítulo-Derechos y libertades- a excepción de los que se vean expresamente limitados por el contenido del fallo condenatorio, el sentido de la pena y la ley penitenciaria. En todo caso, tendrá derecho a un trabajo remunerado y a los beneficios correspondientes de la Seguridad Social, así como al acceso a la cultura y al desarrollo integral de su personalidad". Semejantes declaraciones señalan un camino garantista en la comprensión del Derecho penal y de sus consecuencias jurídicas, en especial de la pena de prisión, además de poner los mimbres argumentales de la función de la pena en un Estado de semejantes características.

Cierto es que la declaración de inicio del artículo 25.2 no es absolutista ni excluyente de otras posibilidades que se muevan dentro del marco establecido por el precepto. Quiero decir con ello que la susodicha proclamación constitucional no ha de ser interpretada sobre el bastión de una irreflexiva omnipotencia preventivo-especial que podría llevar, como ha puesto de manifestó un sector de la doctrina, a consecuencias inasumibles, sino que lejos de anular el principio de culpabilidad o los posibles fines preventivos generales de la pena únicamente conduce a reconocer, de manera orientativa, la exigencia de metas preventivo-especiales en la ejecución de la pena cuando ello sea posible socialmente, lo que no significa, en sentido contrario, que tal finalidad resocializadora no tenga relevante incidencia y conlleve determinadas consecuencias que pueden afectar al resto del sistema penal. 
En todo caso, el planteamiento constitucional moldea la función no solo del Derecho penal sino también, y como derivación, de la propia pena. Este va a ser el primero de los argumentos por los que ha de caminar mi discurso: su ensamblaje constitucionalista volcado entre la ferrajoliana distinción entre constitucionalismo principialista y constitucionalismo garantista, por este último, que en el ámbito punitivo y en el de mi propia interpretación significa una relevante atracción hacia principios normativizados que, a manera de derechos fundamentales, contienen mandatos de optimización de las respuestas punitivas en el Estado social y democrático de Derecho y suponen, al mismo tiempo, formas de control de la constitucionalidad de dichas leyes penales, bajo el soporte de un positivismo alejado de cualquier identificación entre Derecho penal y Moral.

Llegados a este punto es conveniente aproximarnos al núcleo esencial de esta exposición basada fundamentalmente en dar respuestas a una pregunta esencial por multiforme para la comprensión de tan complejas, controvertidas y, veces, contradictorias instituciones en relación al ámbito social donde se ubican: ¿Cuál es la legitimación y función del Derecho penal y de la pena en una sociedad democrática?

La contestación inmediata, generalista y discutible, puede ser que se trata de un importante mecanismo de control social que intenta proteger la pacífica convivencia de los ciudadanos y que se legitima en su necesidad, "amarga necesidad" que refería el Proyecto Alternativo de Código penal alemán. Sin embargo, semejantes hipótesis explicativas son revisadas en la actualidad desde enfoques críticos que pretenden conducir hacia la idea de una permanente crisis del Derecho punitivo; hipotética, en todo caso, diría yo, pues la tendencia legislativa no solo en España sino en prácticamente todo el Derecho comparado camina hacia presupuestos de expansión que, en ocasiones, resultan sumamente discutibles cuándo no sorprendentes para una moderna y legitimada en parámetros democráticos y sociales ciencia punitiva. El aval doctrinal que dan ciertas concepciones dogmáticas, entre las que destaca el funcionalismo radical, y su brazo ejecutor, el Derecho penal del enemigo, a dichas apetencias expansionistas fortalece las formas organizadas de poder, esto es los Estados, el desarrollo de sus inclinaciones represivas generalmente disimuladas en invocaciones a la seguridad de los ciudadanos en lo que lo útil, lo funcional, parece hacer retroceder 
los niveles del imprescindible garantismo penal y aboca, cada vez con mayor frecuencia, a una utilización indiscriminada del Derecho punitivo y al continuado uso de la pena de prisión.

La cuestión, incluso admitiendo partir de la supuesta crisis de identidad del Derecho penal, es concretar cuáles son los niveles más adecuados en los que se ha de mover el análisis para llegar a conclusiones satisfactorias. Porque las preguntas se agolpan de inmediato ¿Es el sistema el que está a debate o su comprensión más tradicional? ¿Son tal vez sus atrofiadas formas de reacción? ¿Es su restringido ámbito territorial de aplicación poco válido en un entorno económico, social y cultural cada vez más globalizado? ¿Es su debilitado mecanismo estructural frente al avance imparable de las nuevas tecnologías? ¿Es su, a veces, desproporcionada utilización disimuladora de determinadas carencias generalmente de políticas sociales, económicas, culturales y educativas por parte de los Estados? Preguntas de no fácil respuesta y menos en un ensayo limitado en el tiempo y en el contenido como éste, pero que hay que reconducir a la propia esencia del Derecho penal y de su función y realidad, necesaria, en el Estado democrático.

Se ha dicho y creo que con razón, al menos como planteamiento introductorio, que el Derecho penal se manifiesta como un instrumento al servicio de la Política criminal y ésta es una parte de la política general del Estado, lo que convierte a aquél en un instrumento político. En tal sentido un análisis histórico por escueto que sea nos pone de manifiesto las derivaciones que las distintas ideologías han tenido para la compresión del Derecho penal. Desde el Derecho penal liberal, concebido sobre las ideas de los más destacados ilustrados y reformadores hasta las hipótesis negadoras de su realidad, desarrolladas por anarquistas históricos y marxistas radicales, o las partícipes de la unión entre socialismo y derecho, se llega a un muy relevante abanico de hipótesis.

Sobre semejante comprensión y la aceptación inevitable de la realidad y necesidad social del Derecho penal en la actual estructura de los Estados hay que delimitarlo, en cuanto a estos y en relación a sí mismo antes de afrontar su función en el modelo de Estado que defiendo. 
En las variables actuales no se está en la dicotomía Estado capitalista burguésEstado socialista, sino en la dinámica del Estado social y democrático de Derecho que asume en su amplia concepción ideas y premisas de las diferentes ideologías conservadoras o progresistas pero sobre el sostén de los principios básicos de dicho Estado, democráticamente aceptado. De semejante manera sucede con el Derecho penal, según lo concibo, no adscrito a una u otra concepción ideológica, como se pretendía hasta muy recientemente, sino asentado sobre dichos principios fundamentales que derivan de la Constitución, que lógicamente también es ideología, pero mixtura de ideologías. Así el Derecho punitivo es mayoritariamente aceptado. Lo fundamental, entonces, no es el debate sobre su necesaria presencia en los sistemas jurídicos actuales sino su contenido, su alcance o su función. Por ello se habla de un Derecho penal de reglas, de un Derecho penal de principios, de un Derecho penal simbólico, de un Derecho penal mínimo, de un Derecho penal para la globalización; planteamientos, algunos de ellos discutibles, que, sin embargo, se instalan más en el futuro que en un pasado, de gran importancia dogmática, pero en el que bastantes de sus supuestos, que parecieron claves, han acabado enterrados con la exclusiva pretensión de ser revividos en clave de análisis histórico como mecanismos interpretativos para la evaluación del presente o para fortalecer, como tales, algunas de las orientaciones político-criminal de futuro.

En tal contexto y advertida, por mi parte acaso con excesiva reiteración, su referencia constitucional que lo convierte, aunque sea en una teórica versión en negativo, en uno de los baluartes más representativos del Estado social y democrático de Derecho, desde el momento en que sirve al mantenimiento de la estructura social y estatal programada por la propia Constitución, es conveniente para avanzar con precisión en este discurso concretar su función en un sistema de tales características.

Las propuestas doctrinales en este sentido han sido múltiples y con diversos enfoques y estimaciones. Desde la exclusivista de garantizar los caracteres principales e indispensables de la vida en comunidad, de rancio abolengo temporal, pasando por la más moralizante dual de protección de bienes jurídicos mediante la tutela de los elementales valores de acción ético-social y de prevención dirigida a hombres que carecen de capacidad en un amplio margen para vincularse a normas ético-sociales, en 
su versión más actualizada la protección de la firmeza de las expectativas normativas esenciales frente a la decepción que conlleva la defraudación de aquellas, hasta las bifrontes basadas en la protección y motivación o protección y prevención.

En este amplio abanico de posibilidades me inclino por la doble función de protección y prevención. Sin embargo, semejante afirmación ha de ser concretada en términos de delimitar su alcance y conexión entre ambas. Con respecto a la primera, en mi opinión la función de protección que con primacía ha de realizar el Derecho penal se refiere a la tutela de bienes jurídicos del ciudadano y de la propia comunidad, bienes individuales y bienes colectivos unidos bajo el sostén del carácter estatal de la norma punitiva. En dicha acepción el concepto de bien jurídico toma un papel esencial e indiscutible.

No es, sin embargo, esta valoración del bien jurídico en la función de protección doctrina pacífica, aunque sí mayoritaria. El funcionalismo radical jakobsiano, por ejemplo, critica con cierta dureza semejante prevalencia al entender que la misión del Derecho penal va más allá de la mera protección de bienes jurídicos, al menos en una visión restrictiva, en cuanto la lesividad social supone algo más que la conculcación de valores ideales. Sobre esta comprensión el Derecho penal se ve como un instrumento de apoyo a la funcionalidad del sistema, a su capacidad de organización, al aseguramiento de sus competencias y al cumplimiento concreto de cada uno de los roles asignados a los ciudadanos integrantes de dicho sistema; en definitiva, tiene como función prioritaria el mantenimiento de la vigencia de la norma, de la confianza en el Derecho, el Derecho penal como estabilizador de la norma. La operatividad de semejante crítica y la propuesta de fidelización de la norma conducen a dudosas conclusiones no aceptadas por mí, entre ellas la poco convincente desacreditación de bien jurídico que realiza y la débil argumentación en que erige su opción alternativa. En todo caso, como advierte algún otro sector doctrinal, la cuestión cabe reducirla a una definición precisa y clara del bien jurídico, no de construir nebulosas hipótesis poco fundamentadas de derribo de éste como valor esencial en la función de protección que cumple el Derecho punitivo. 
Aclarado lo anterior, el fijar mi posición al respecto se me presenta bastante más sencillo, aunque difícilmente se pueda negar, ni yo lo pretendo, la falta de concreción conceptual por la que camina la comprensión del bien jurídico. No obstante, dos son las direcciones más sobresalientes al respecto: por un lado, las denominadas constitucionalistas, en su versión más pura: por otro, las de orientación sociológica. Adscrito a las primeras con ciertos matices me muevo inicialmente en línea roxiniana de concebir el bien jurídico "como circunstancias dadas o finalidades que son útiles para el individuo y para su libre desarrollo en el marco de un sistema social global estructurado sobre la base de esa concepción de los fines o para el funcionamiento del propio sistema"; por lo que el punto de arranque adecuado en relación al bien jurídico parte de la idea de reconocer, en primer lugar, que la única restricción previamente establecida para el legislador deviene de los principios constitucionales $\mathrm{y}$, en segundo, que un concepto de bien jurídico vinculante político- criminalmente solo puede provenir de los objetivos modelados por el texto constitucional descriptor del Estado social y democrático de Derecho fundamentado en la libertad del ciudadano, por medio de los cuales se fijan necesarios límites, en forma de principios, al ius puniendi estatal, como, entre otros, son: el de legalidad, culpabilidad, proporcionalidad, necesidad de pena, subsidiariedad, ultima ratio o intervención mínima.

Todo ello no elude ni aleja la pretensión de algún sector de que el contenido y los criterios de selección de los bienes jurídicos haya que buscarlos en la realidad social. Realidad social que como concepto no deja de ser ambiguo, y en el que interfieren intereses económicos, sociales, personales, mediáticos, etc., muy diversos y, a veces, enfrentados. Para aunar todas esas hipótesis es conveniente, en línea con lo explicitado en tal sentido hasta ahora, en los Estados democráticos y de Derecho una norma directriz obligatoria para la convivencia, es decir la Constitución, que, siempre, será más adecuada, por su forma de elaboración, por su representación del sentir ciudadano y por sus presupuestos formales y materiales, como vehículo garantizador de las libertades y necesidades sociales, que expresiones, tan carentes de precisión, como las de condiciones valiosas, funcionalidad y disfuncionalidad del sistema social estatal, valores ético-sociales o fidelidad a la norma. 
En definitiva, la opción que defiendo en relación al bien jurídico se fundamenta en dos parámetros básicos: por un lado, la proclama que hace el artículo 1.1 de la Constitución sobre el Estado social y democrático de Derecho señala, en línea con la más actual política criminal, la prioritaria función del Derecho penal en la protección de bienes jurídicos; por otro, que dichos bienes jurídicos hallan su fuente legitimadora primaria en los valores e intereses constitucionales y asimismo, como relevante complemento para su fundamentación, en las realidades sociales en las que se desarrolla la propia concepción formal del Estado. Paralelamente a todo ello tengo que significar que mi adscripción a semejante planteamiento no es vocacionalmente ciega ni partidariamente acrítica. La referencia constitucional es de utilidad y me asegura más eficiencia para resolver los problemas planteados que cualquier otra, lo que no significa que la ofrezca como panacea malabarista de solución de todos los problemas actuales del Derecho penal, en sí misma los tiene pero bien es cierto que menos que otras opciones y, sobre todo, ofrece un indudable carácter garantista imprescindible para un Derecho y una política criminal modernos y adaptados a las exigencias de los Estados materialmente democráticos.

La destacada función de protección del Derecho penal requiere necesariamente ser completada. Su exclusiva presencia, con ser trascendental, se muestra insuficiente en cuanto aislada se aleja del hecho punible cometido y del bien jurídico concretamente lesionado por la conducta infractora, pues para ésta el derecho llega tarde, el delito ha sido realizado, la consecuencia jurídica derivada de tal acción cabe ser planteada como una exclusiva reacción al mal cometido sin más pretensión o, por el contrario, con visión de futuro para prevenir la comisión de nuevos delitos. Cierto es que la inclinación más primaria del Derecho penal supone la reacción con un mal frente a la comisión de una conducta estimada delictiva, como medio de protección, en cualesquiera de sus variantes, de la sociedad. Esto se puede llevar a cabo, simplemente con la idea de compensar con una pena justa el mal cometido por el delincuente o con la de evitar a través de su incidencia en el sujeto agente o en la generalidad de la comunidad que en el futuro se ataquen otra vez los bienes jurídicos protegidos por el Ordenamiento jurídicopenal. 
Esta última es la vía más lógica para lograr la misión básica que el Derecho penal persigue. Por consiguiente, es la segunda variable de mi planteamiento al respecto: la protección de bienes jurídicos ha de mirar al futuro, al comportamiento del delincuente o de otras personas que todavía no han delinquido, lo que significa una opción de propuestas punitivas eminentemente preventivas, que se consolidan a través de la prevención general y especial. Como ha sido escrito, con excelente criterio, el Derecho penal de la prevención es el Derecho penal racional y moderno.

Llego así de manera conclusiva a reafirmar mi criterio inicial edificado en que la función básica y legitimadora del Derecho penal es la protección de la sociedad mediante la concreta tutela de bienes jurídicos lo que se ha de conseguir a través de la segunda de las funciones que racionaliza la actuación punitiva y que es la de prevención, punto de encuentro y de orientación identificadora con la propia función de la pena.

II.

De la función del Derecho penal, lo acabo de decir, se camina, como derivación de una de sus consecuencias jurídicas, hacia la función de la pena en parámetros de instrumentos de real protección diseñados bajo la estructura de sus propios fines preventivos. No obstante, y a pesar de esta genérica afirmación, ello no se traduce en un automatismo conceptual identificativo de ambas hipótesis, puesto que la función de aquél no completa en su totalidad la forma, finalidad e incluso función de la pena para lograr la eficacia requerida por el Estado para el logro de los objetivos demandados al Derecho punitivo. A tanto puede llegar esta idea que algunos sectores doctrinales han invertido la influencia en la opinión que del concepto de pena del cual se parta, de su justificación y fines, dependerá, en gran medida, la propia concepción del Derecho penal que se defienda, desde la comprensión de que la función de éste depende de la que se le asigne a la pena, como medio más característico de la intervención penal, de la que incluso usa su nomenclatura.

La pena, y dentro de ella la de prisión, ha sido y es el instrumento más demandado dentro del sistema penal, y uno de los más visibles del Ordenamiento jurídico en general, y, a la vez, el más utilizado por una sociedad donde parece crecer la 
sensación de peligro, en bastantes ocasiones de manera no constatada, hasta convertirse en una hipotética sociedad de riesgo en la que se dan impulsivas reacciones a convicciones allanadas por influencias mediáticas y por determinadas ideologías que conducen al incremento de la alarma social y la permanente exigencia de un endurecimiento de los medios de reacción penal. Situación expansionista que parece no tener freno ni límite incluso con el acceso al poder en los más variados sistemas y gobiernos de grupos políticos de convicciones progresistas que por su vinculación ideológica más comprometida, en teoría, con acciones sociales parecieran más comprometidos con un garantismo penal, con un derecho de la prevención, integrador socialmente y recuperador de los ciudadanos que delinquen sobre políticas sociales y criminales sustentadas en mecanismos alternativos que alejen, en la medida de lo posible, la comisión de delitos y el uso desmesurado de la pena.

Ante esta ondulante progresión de expansionismo, el especialista, en este caso el científico del Derecho penal, ha de estar alerta para reaccionar ante los posibles excesos punitivos con propuestas sólidas que se enmarquen en el respeto a los principios básicos del Estados social y democrático de Derecho para conseguir sobre ese interesante apoyo legitimador propuestas político-criminales que mejoren el sistema tanto del Derecho penal en general como el de penas, en particular. Esto último es lo que va a ocupar el resto del discurso. Para ello voy a atender a dos reflexiones generales con diversificados parámetros de valoración: por un lado, aludir a los que, según mi opinión, son principios básicos que han de marcar el sistema de penas en un Derecho penal de garantías; por otro, desarrollar, con la brevedad y concisión que una presentación de estas características requiere, mi posición sobre la teoría de la pena para de tal manera alcanzar la identidad de su función a través de la concreción valorativa de los aspectos más destacados en cuanto a contenido, justificación y fines.

Señalar con respecto a lo primero que cualquier planteamiento que pretenda valorar un determinado sistema de penas y que, además, se esfuerce en desarrollar propuestas político-criminales requiere fijar los principios básicos que configuran la imprescindible referencia de un Derecho penal racional y moderno ubicado en un Estado social y democrático y de Derecho. La consagración real y el respeto máximo a principios tales como el de legalidad, con sus correspondientes garantías, los de 
dignidad de las personas, proporcionalidad, igualdad, culpabilidad, humanidad, necesidad, intervención mínima y libre desarrollo de la personalidad son absolutamente imprescindibles.

Posiblemente la estrella en cuanto a relevancia y, al mismo tiempo, controversia de entre ellos en relación a la pena sea el de culpabilidad. Curiosamente fortalecida en su trayectoria histórica por la teoría de la retribución adquiere en la actualidad presencia importante en las opciones preventivas, en cuanto se presenta como medio de limitación y fundamentación de la pena. Incluso en esta línea de valoración se llega a plantear que una pena que sobrepasa la medida de la culpabilidad atenta contra la dignidad de la persona, con lo que dicha culpabilidad traducida en principio programático del artículo 1 de la Constitución, adquiere rango constitucional, en atención a su función limitadora, lo que para una interpretación interesada en la relevancia de dicho principio, al dimanar de manera inmediata del de dignidad, es posible atribuirle en todo caso un peso superior al de otros principios que coyunturalmente pudieran entra en conflicto con él.

No es esta última respuesta pacífica en la doctrina, aunque sí, en términos generales, lo es para mí. Algunos sectores de aquélla se empeñan en ir dejándola sin contenido progresivamente para introducir otras opciones sustitutivas. Por ello, porque se presenta, en mi convicción, como uno de los pilares esenciales del sistema punitivo, tanto del propio delito como, y es en esta exposición lo de mayor interés, de su consecuencia jurídica más importante, la pena, aunque al mismo tiempo sea, sin embargo, una de las cuestiones más debatidas y de más compleja delimitación en la doctrina penal desde el inicio como ciencia. Su concepto y función están sometidos a fuertes y renovadas críticas, prioritariamente encaminadas a su comprensión más tradicional.

En consecuencia, conviene en este punto detenerme, aunque de manera breve, para mostrar también con ella mi posición y su activa presencia dentro del sistema de penas que propugno, tanto más en cuanto las normas penales no ayudan en exceso a una auténtica delimitación conceptual de semejante institución, quedando, destacadamente, tal objetivo para las reflexiones dogmáticas abiertas a las más complejas y, a veces, encontradas opiniones. Con razón ha sido escrito, que el fenómeno de la culpabilidad 
puede estimarse y de hecho ha discurrido desde perspectivas científicas muy diferentes: es tanto una experiencia fundamental religiosa y moral del hombre como una situación sicológica o sociológica, tanto una vivencia y un reconocimiento individuales como una parte de la realidad social, tanto un proceso dinámico (llegar a ser culpable y sentirse culpable) como una magnitud valorativa (juicio de culpabilidad sobre otro).

Dichas fluctuaciones han llevado a determinados excesos normativistas, sobre todo del finalismo más radical, a la ambigua contradicción irresoluble entre determinismo e indeterminismo, a la huida hacia fundamentos preventivos, en esencia de prevención general, hasta llegar a su sustitución, al intento no válido de cambio por el principio de proporcionalidad, a propuestas basadas en una motivabilidad no especialmente verificable, a versiones limitativas, a la utilización de la imputación personal como criterio revelador de un nuevo planteamiento alternativo, a la ubicación de la culpabilidad junto con la necesidad de pena dentro de la categoría de responsabilidad, que hacen dudar de muchos de ellos como adecuados, en su totalidad, para dar coherente respuesta a la comprensión conceptual y su significado en la teoría jurídica del delito y a la relación con la pena de la culpabilidad, y hacen pensar que, en no pocos casos, se está ante un divertimento intelectual de cambio de etiquetas, bien estructurado, pero no alejado del sentido tradicional de aquélla, superados sus ramalazos éticos-moralizantes y ontológicos.

Acaso lo procedente para solventar los problemas y contradicciones existentes entre las diversas teorías sea, con las cautelas precisas que cualquier concepción ha de tomar para no desbordar la coherencia de sus planteamientos, partir, como base, de una revisión efectiva del concepto tradicional de culpabilidad desligándolo de sus cargas más ideológicamente conservadoras y metafísicas para ponerlo en relación con la pena y el Derecho penal preventivos, construcción defendida a lo largo de este discurso como la más válida, y con aquellas ideas más sobresalientes y convenientes de asumir para semejante finalidad de las numerosas tendencias que en torno a la culpabilidad han existido.

En tal línea de argumentación he de presentar dos premisas que inicialmente han de marcar las previsiones posteriores. La primera de ellas, la afirmación rotunda de la 
necesidad de mantener la culpabilidad como categoría destacada de la teoría del delito $\mathrm{y}$, en consecuencia, el principio de culpabilidad en todas sus variables, diferenciada, pero en íntima conexión en cuanto a fundamento, limitación y fines de la pena, que no pueden ser otros que los de naturaleza preventiva, con la prevención, más en concreto, por ser lo más destacado de cierta tendencia doctrinal, con la prevención general que, en ningún caso, puede absorber a aquélla ni transformarla en los parámetros de ésta.

La segunda, el relevante carácter garantista que ofrece semejante idea de culpabilidad en la realidad jurídico-penal del Estado social y democrático de Derecho, como límite del ius puniendi dentro de éste y también, como derivación, del fundamento de la pena y de su propios límites, especialmente el superior, evitándose con esta concepción y alcance que pueda verse contaminada en su esencia por indicaciones radicales de utilidad social, conducentes a una completa funcionalización del sujeto delincuente; contradictoria posiblemente con la propia iniciativa real de prevención pues, en lenguaje roxiniano, no parece factible que sea el mejor camino el divulgar entre la población que el sí y el cómo de la pena no se circunscribe a lo que uno ha hecho con la actitud que sea, sino de lo que al juez le parezca necesario para el restablecimiento de la confianza en el Ordenamiento, y que la culpabilidad se puede afirmar o negar sin que dependa de la persona actuante sino de factores que no tienen nada que ver con ella, de modo que "se le convierte en un juguete de las respectivas circunstancias", lo que a buen seguro generará intranquilidad y difícilmente logrará estabilizar el sistema.

Se llega de este modo al núcleo esencial de nuestra reflexión: el fundamento de la culpabilidad. La respuesta es clave para una adecuada comprensión de su ubicación, contenido y alcance. Ciertamente no son fáciles de ubicar los componentes precisos a analizar para llegar a una válida conclusión al respecto, pero parece de inevitable aceptación, como ha puesto de manifiesto una buena parte de la doctrina, que la culpabilidad tiene como presupuesto lógico la libertad de decisión de las personas, aunque la cuestión, a partir de ahí, deriva hacia la difícil concreción de tal aseveración. No obstante lo anterior, se me antoja necesario trasladar la cuestión al terreno normativo, con todas sus consecuencias, y situarla en dos puntos básicos: el poder actuar de otra manera o "el poder evitar" por parte del autor la realización delictiva y el 
juicio de reproche, transformado en un juicio de culpabilidad desde una perspectiva estrictamente jurídica.

En cuanto al primero, parto de la premisa inicial que supone el admitir la dificultad de demostrar la existencia de la libertad humana desde el punto de vista de una teoría del conocimiento o desde una científico-natural; sobre alguna de tales dimensiones se puede precisar como una hipótesis no verificable, en la línea de los críticos a la culpabilidad tradicional. Ahora bien, ello no comporta su negación como categoría jurídico-dogmática ni tampoco incluso la refutación del poder actuar de otro modo como presupuesto sino simplemente que la susodicha comprensión no es válida y requiere un nuevo enfoque definidor.

Este ha de comenzar, como ya he indicado, por alejar al Derecho penal de cualquier debate metafísico o ético-moralizante sobre la libertad de voluntad e incluso de sus aspectos antropológicos, caracterológicos o categoriales, al estilo de como los han plateado algunos autores fundamentalmente alemanes, lo que supone dejar la constatación empírica individual para ir a una normativamente determinada, en cuanto que la persona, ciudadano del Estado, ha de ser tratada como libre, dada su capacidad intacta de autoconducción y, con ello, una dirigibilidad normativa que significa a su vez una constatación empírica colectiva o social, tal y como ahora lo voy a exponer, desde la óptica personal que defiendo.

En un Estado social y democrático de Derecho que ensalza la libertad como valor superior de su Ordenamiento jurídico, el Derecho penal tiene que partir de esa exigencia constitucional de que los ciudadanos son libres, capaces de decidir responsable y autónomamente. Se transforma así, la libertad de acción, en todos sus sentidos, en una exigencia jurídico-constitucional, alejada de cualquier dimensión ontológica. Esta es la premisa inicial del planteamiento a proponer.

Sucede, no obstante, que esta regla general basada en la idea de libertad del individuo como ciudadano de una sociedad libre no puede ser construida de manera absoluta sin excepciones. En no pocas ocasiones semejante posición de libertad para decidir se ve limitada por determinados factores causales que, en alguna de sus variables, son tenidos en cuenta como negadores o anuladores de la hipótesis inicial. En este sentido, se 
evidencia que determinadas personas no poseen esa capacidad de elección al actuar, y en consecuencia no pueden ser atribuidos subjetivamente por el hecho delictivo cometido, ya sea por la edad o por la propia estructura psíquica o biológica del sujeto o por situaciones extraordinarias derivadas del hecho en sí, que impiden al autor obrar de manera distinta a como lo hizo. Semejantes supuestos excepcionales tampoco son fruto de elucubraciones judiciales o dogmáticas, al menos en el Derecho positivo español, sino conceptos normativos que el legislador, valedor último del sentir ciudadano, detalla expresamente en el Texto punitivo.

Asimismo ocurre, con la concurrencia de determinadas situaciones en la ejecución del hecho, igualmente tasadas normativamente, que provocan una nueva neutralización de la capacidad de autodeterminación, con lo que, en paso posterior a la anterior hipótesis, también el autor queda exculpado por no podérsele exigir en el caso concreto una conducta distinta a la realizada, de tal forma entendida no es una causa supralegal de inculpabilidad, tampoco un principio inspirador de las causas de inculpabilidad, aplicable por analogía a los casos no previstos expresamente por el legislador, ni un criterio regulativo del Derecho sino un presupuesto de la culpabilidad determinado expresamente por el legislador, a través del cual acoge un grupo de situaciones en las cuales al individuo adulto, normal y mentalmente sano que ha actuado dolosa o culposamente no se le puede reprochar el uso indebido de la libertad de obrar socialmente reconocida, por no haber podido obrar de otra manera a como lo hizo, manera de actuar que previamente el Código legitima como causa de no exigibilidad. Se llega con estas argumentaciones a una idea de culpabilidad ni absoluta ni inamovible sino relativa y perfectamente adecuada a las exigencias sociales que serán en definitiva las que marquen la pauta de las causas a incluir como supuestos legales de no exigibilidad.

La segunda consideración, ya prácticamente contestada con anterioridad, se refiere al denominado juicio de reproche personal. La culpabilidad se significa en gran parte de la doctrina normativa como un juicio reproche que se dirige al sujeto porque realizó una acción típicamente antijurídica cuando podía, desde una perspectiva jurídica, actuar de otro modo. Tal aseveración también ha sido fuertemente combatida, en razón a los mismos motivos antes enunciados, por determinados sectores doctrinales. Y 
efectivamente, el juicio de reproche, de igual manera, que el poder actuar de otro modo, que lo fundamenta, se ha entendido frecuentemente con unas connotaciones moralizantes no deseables. Este reproche de culpabilidad ha de partir de la certeza jurídica de libertad como presupuesto de la actuación individual y concretarse en una determinación efectiva de que el hecho atribuible a esa persona puede serle también responsabilizado en la medida en que ha actuado libremente de manera antijurídica cuando pudo hacerlo de otra manera. Como ha señalado la doctrina, una culpabilidad sin reproche, es decir, al margen de la congruente actitud participativa, es una contradictio in adjecto, pues la culpabilidad no es sino atribución de la infracción normativa a su autor y esto ya supone un reproche. En esta línea, el reproche de culpabilidad no ha de ser concebido, en ningún caso, como recriminación moral o regañina ética añadida sino como verificación versus imputación de haber materializado un hecho antijurídico que pudo no realizar, según lo fijado por las diversas instancias de control a través de las normas.

Semejante dicotomía, reprochabilidad-poder actuar de otro modo, imprescindible y coadyuvante entre sí, ha de ser entendida necesariamente en los términos a los que aludo para conseguir la visión de la culpabilidad, moderna, racional y fundada jurídicamente, que propongo. El giro que se ha pretendido dar a semejante tesis, vista desde su ubicación más tradicional, ajena a lo aquí planteado, del poder del sujeto individual hacia "la capacidad del hombre medio" o "el poder de actuar de la mayoría de las personas" u otras todavía más complejas, no deja de presentar parecidos inconvenientes de concreción interpretativa a la tesis más rancias. Por ello la base esencial de su comprensión no puede ser otra que la propia declaración constitucional de libertad de los ciudadanos, como regla general, y las tasación normativa, jurídicamente concretada, de las posibles excepciones que justifican la no libertad del sujeto actuante. Se ha dicho en este o parecido sentido, que se está aludiendo, en todo caso, a una persona a medida, vinculada con los valores jurídicamente protegidos. No es exactamente así, sino al ciudadano libre en un Estado social y democrático de Derecho, cuyo fundamento es la propia esencia de dicho Estado, que, sin embargo y como no puede ser de otra forma, atiende en clave penal a ciertas excepciones normativamente marcadas y fundamentadas en las valoraciones sociales al respecto, concretadas en la propia elaboración democrática de las normas, que afectan tanto a la teoría jurídica del delito como a la de la pena. 
Junto al principio de culpabilidad, ampliamente detallado, cabe destacar, ya con la urgencia del espacio y del tiempo, el de necesidad de pena que se proyecta en una doble dimensión: desde la conminación penal abstracta y desde la imposición y ejecución concreta. En la primera enlaza con la naturaleza de ultima ratio que al Derecho penal se le asigna y con su carácter fragmentario, y con la de ultima ratio de la ultima ratio de la propia pena; en la segunda con la fijación individualizada de qué pena es innecesaria y perjudicial para la sociedad o para el propio delincuente. También e íntimamente conectados con los anteriores, los principios de humanidad y de proporcionalidad. Aquel señala que todas las actuaciones y relaciones que el Derecho penal tipifica se han de reglar sobre la base de una vinculación recíproca, de una responsabilidad social hacia el ciudadano que delinque; en resumen de una comprensión humanitaria y social sobre el delincuente, que se proyecta fundamentalmente en el momento de ejecución de las penas, pero asimismo en su programación abstracta. El de proporcionalidad, en su vertiente restrictiva, indica que la gravedad de la pena ha de corresponderse con la gravedad del hecho, en cuanto a la intensidad del ataque al bien jurídico protegido realizada por el sujeto, aunque algunos autores le otorgan una comprensión más extensiva al conceptuar dicho principio en su formulación amplia integrado en tres subprincipios: idoneidad, necesidad de respuesta penal y proporcionalidad en sentido estricto o ponderación.

También merece mención especial el principio de legalidad, referencia nuclear en toda la estructura del Derecho penal y destacado igualmente en el sistema de penas. Tanto en su vertiente de garantías individuales - para el interés de este discurso, las garantías penal, jurisdiccional y de ejecución- como de elaboración de las normas -lex stricta y certa-. Acaso es este último ámbito el que mayor incidencia presenta en relación con las penas en particular. La exigencia de taxatividad y certeza se hace más intensa en dicha parte del Derecho penal, en la que con cierta frecuencia se acude a indeterminaciones que pueden afectar, además, a otro principio, estrechamente conectado, el de seguridad jurídica.

En el sentido indicado se podrían poner evidentes ejemplos de distanciamiento entre contenidos del Texto punitivo o planteamientos reformistas todavía en gestión y una adecuada ejecución de estos principios y su incidencia negativa en nuevas fórmulas 
de expansionismo de la pena de prisión. Valga a título de muestra, exclusivamente con esta perspectiva, la pretendida incorporación a través del Anteproyecto de Ley Orgánica por la que se modifica la Ley Orgánica10/1995, de 23 de noviembre, de 17 de octubre de 2012 (en adelante Anteproyecto 2012), en fase de tramitación, de la pena de prisión permanente para supuestos de excepcional gravedad -asesinatos especialmente graves, homicidio del jefe del Estado o de su heredero, de jefes de Estado extranjeros y en los supuestos más graves de genocidio o de crímenes de lesa humanidad-. Se trata, según dice la Exposición de Motivos, de dar una respuesta extraordinaria mediante la imposición de una pena de prisión de duración indeterminada (prisión permanente), si bien sujeta a un régimen de revisión: tras el cumplimiento íntegro de una parte relevante de la condena, cuya duración depende de la cantidad de delitos cometidos y de su naturaleza -a partir de los 25 o 30 años según los casos-, acreditada la reinserción del penado, éste puede obtener una libertad condicionada al cumplimiento de ciertas exigencias, en particular la no comisión de nuevos hechos delictivos.

Sobre tal perspectiva, dicha incorporación se justifica, según la Exposición, en: Uno, la prisión permanente revisable garantiza la existencia de un procedimiento judicial continuado de revisión lo que la aleja de la inhumanidad de otras penas de larga duración, treinta o cuarenta años, cuya especial problemática es la falta de un horizonte de libertad; Dos, no constituye, por ello, una suerte de "pena definitiva" en la que el Estado se desentiende del penado, por el contrario, se trata de una institución que compatibiliza la existencia de una respuesta penal ajustada a la gravedad de la culpabilidad, con la finalidad de reeducación a la que debe ser orientada la ejecución de las penas de prisión; Tres, se trata, en realidad, de un modelo extendido en el Derecho comparado europeo que el Tribunal Europeo de Derechos Humanos ha considerado ajustado a la Convención Europea de Derechos Humanos, que ha declarado que cuando la Ley nacional ofrece la posibilidad de revisión de la condena de duración indeterminada con vistas a su conmutación, remisión, terminación o libertad condicional del penado, esto es suficiente para dar satisfacción al artículo 3 del Convenio (cfr. SSTEDH 12-2-2008, caso Kafkaris vs. Chipre; 3-11-2009, caso Meixner vs. Alemania); cuatro, el Consejo de Estado español ha tenido oportunidad de pronunciarse sobre la constitucionalidad de las penas de duración indeterminada -pero revisables-, al informar con relación a la ratificación por España del Estatuto de la Corte 
Penal Internacional, en el que está prevista la posible imposición de una pena de prisión permanente.

Semejantes argumentaciones que, obviamente, son lo suficientemente sólidas para el debate no evitan desde nuestro punto de vista la prepotencia de una marcada línea retribucionista-preventivo general que su desarrollo pone de manifiesto, por más que se quiera justificar en dudosos parámetros resocializadores y reeducadores del delincuente tanto más cuanto el máximo de pena a cumplir en nuestro Texto punitivo vigente, cuarenta años, parece suficiente para los supuestos de extrema gravedad, así como su escala inmediata de treinta y veinticinco años, por lo que dicha incorporación la valoro como innecesaria, además de incierta adecuación a los parámetros exigidos por el artículo 25.2 de la Constitución -como pone de manifiesto el Informe emitido por el Consejo General del Poder Judicial al respecto, resulta cuanto menos dudoso que una privación de libertad potencialmente perpetua sea conciliable, en un ámbito estrictamente interno, con la reinserción contemplada en el susodicho artículo 25.2 de la Constitución-, por el mandato de determinación y certeza del artículo 25.1, derivado del principio de legalidad o por infracción de la prohibición de penas o tratos inhumanos o degradantes (artículo 15), aunque sean revisables.

La valoración y efectividad de dichos principios junto a la forma en que el sistema se enfrenta a la función y fines de la pena, y a las soluciones de las posibles antinomias entre prevención general y especial pueden servir para delimitar e interpretar los contenidos estructurales del propio sistema, proyectados en determinados aspectos recurrentes e imprescindibles de atender a fin de obtener conclusiones válidas para los objetivos político-criminales que busca fomentar este discurso. Para ello, y como colofón final, es imprescindible mostrar mi posición al respecto.

Advertir antes que parto obligado sobre afirmaciones dadas por sabidas, de imposible desarrollo en una intervención de estas características, en torno a los históricos debates sobre retribución-prevención en relación al fundamento y a los fines de la pena que van desde los más concienzudos defensores de las nuevas especies de retribucionismo actualizado en las plumas de tendencia jakobsiana hasta las utópicas y fracasadas predicciones abolicionistas, en ocasiones brillantes por solidarias, que ven la pena como injusta, inútil y hasta perjudicial, pasando por todo el cargamento de teorías 
unitarias, preventivas, preventivo generales positivas, consecuencialistas, y demás opciones que durante tanto tiempo han presentado los más dispares sectores de la doctrina. Adelantar ya mi adscripción a una teoría unificadora preventiva.

Desde una percepción comprometida con todo lo anteriormente expuesto en clave de principios, la pena hay que estimarla, no cabe ser de otra manera, como un mal, en la idea de acto de fuerza que la sociedad emplea para su defensa y que supone para el individuo que la recibe una privación de derechos. Esto no significa que se esté adelantando ningún otro criterio pues ese mal no tiene por qué significar retribución. Se justifica en su necesidad para la protección de bienes jurídicos a través de la prevención. Su fundamento es doble: por un lado, la culpabilidad, que, como ya he dicho, juega esencialmente como limitación de la intervención; por otro, la necesidad, y aquí enlaza con la justificación: una pena adecuada a la medida de la culpabilidad únicamente puede fundamentarse cuando realmente sea necesaria para la protección de la sociedad y del individuo; si no lo fuera para atender a las exigencias preventivas no debe de ser aplicada. La culpabilidad juega un notable papel de garantía: cuando la pena adecuada a la culpabilidad entre en conflicto con los fines preventivos de la pena, el límite superior será invariable, mientras que el límite inferior puede ceder en disminución e incluso en sustitución de la pena si los fines preventivos así lo demandan, con la única limitación de que las causas de disminución o sustitución vengan legalmente establecidas por la ley.

Con tales pilares, el edificio construido tiene sus cimientos en dos grandes columnas: una, en un planteamiento unificador como este, alrededor de la prevención, no cabe ninguna ventana para la retribución, ni en hipótesis marcadas por un simple acompañamiento secundario junto a la prevención; otra, como complemento argumental de lo anterior, que deriva en principal, el fin de la pena únicamente ha de estimarse como preventivo, tanto preventivo-general como preventivo especial.

Para concretar todavía más esta opción es conveniente situarla en la práctica de su realidad social, sobre tres fases generalmente admitidas por la doctrina penal: la primera, la de conminación legal, tiene un marcado carácter preventivo general, pues la pena fijada en la ley con anterioridad a la comisión del delito se dirige a la colectividad y se fundamenta y justifica en la necesidad para la convivencia a través, por su función primaria reiteradamente aludida en esta intervención, de la protección de bienes 
jurídicos; la segunda, la de determinación e imposición, la justificación es la misma, pero para su fundamento junto a la necesidad hay que situar la culpabilidad, con el carácter garantista que le he otorgado, los fines son preferentemente preventivosgenerales al suponer la determinación e imposición de la pena una confirmación de la amenaza abstracta tipificada previamente en la ley, se está sirviendo esencialmente a dichos criterios preventivo-generales, mas puede suceder, no obstante y de manera básicamente puntual, que en ciertos casos la aplicación de una pena juegue como elemento de prevención especial cuando incida en el delincuente frente a una posible reincidencia; la tercera, la de ejecución, se vuelve a justificar y fundamentar en su necesidad para los fines preventivos, los cuales se encaminan, en este ciclo ejecutivo, primordialmente hacia la prevención especial, aunque sin anular efectos preventivogenerales, como pueden ser los producidos por una ejecución efectiva, que vuelve a ratificar la seriedad de la conminación legal para el resto de los ciudadanos, consolidándose así nuevamente las pretensiones preventivo-generales, como ya apuntó el Marqués de Beccaria, para dicha vertiente de las penas, la eficacia de éstas no estriba en su dureza sino en la seguridad de su aplicación, y añado yo eficacia junto a garantías y búsqueda de alternativas.

Situados los rasgos más relevantes de la pena en el sistema democrático, tal como la concibo, y, en consecuencia, su función como instrumento protector de bienes jurídicos, por otro lado función esencial del propio Derecho penal, a través de la prevención general y especial surge otra nueva exigencia de valoración: la relación entre ambas. Parece innecesario afirmar que ésta ha de ser pacifica, caminar por senderos paralelos y, a la vez, coincidentes. Pero no siempre es así, en ocasiones, pocas, pueden presentar disfuncionalidades e incompatibilidades que demanden de un orden cualitativo concreto, sobre todo en casos, como ha sido escrito por algún autor, cuando se toma la prevención especial como reeducación con procedimientos blandos que haga la pena amena y atractiva para el propio delincuente (lo que pocas veces se habrá logrado sí es que se ha seguido firmemente alguna vez) o la general se identifica con el terror intimidatorio. Excluidas radicalizaciones, la conciliación no es compleja es necesaria y sería absurdo no buscarla y conseguirla para el fin prioritario de evitar futuros delitos. 
A pesar de lo dicho, en concreto supuestos, la antinomia de los fines de la pena se da, sobre todo cuando ambas requieren distinta cuantía de pena, lo que conduce a la exigencia conceptual y práctica de decidir al respecto. Un relevante sector de autores, entre los que me encuentro, se manifiestan por la preferencia, en estos seleccionados casos, de la prevención general sobre la especial en atención a la diferente incidencia real y práctica de una y otra: para la primera, en caso de fracaso, afectará a muchos potenciales delincuentes $y$, en consecuencia, a la sociedad en general al relajarse las barreras inhibidores que fundamentan dicha prevención; por el contrario, si lo que falla es la prevención especial, también se crearan conflictos pero, en principio, reducidos a la sola persona que ha cometido el delito en su relación con el Estado y, concretamente, con la administración penitenciaria en la fase de ejecución de la pena. Otro grupo se expresa, avalado por el Proyecto Alternativo alemán y sobre el pensamiento roxiniano al respecto, por la preferencia, que no exclusión, de la prevención especial sobre la general en cuanto la resocialización es un imperativo constitucional, en España orientativo-prioritario, que no puede ser desobedecido donde sea posible su cumplimiento; cuestión esta última que lleva incluso a esta tendencia a asumir, en casos concretos, limitaciones a la prioritaria aceptación de la prevención especial sobre la general.

El conflicto, si lo hubiere, se muestra, en consecuencia, en una bipolarización entre el derecho y la tendencia de la sociedad a tutelar sus intereses más vitales, por un lado, y la exigencia de la persona, ciudadano de un Estado social y democrático de Derecho, aunque haya delinquido, a ser tratada y atendida como tal por la estructura social donde se integra. Mi solución ya ha sido adelantada, en este caso fruto del pragmatismo, en caso de antinomia entre las dos la opción prioritaria ha de ser la de prevención general y ello por las siguientes razones: una, las continuas crisis que han soportado las tendencias preventivo-especiales, acusadas incluso de indeterminación en su aplicación o de posible abandono del principio de culpabilidad, entro otras aseveraciones que no son, sin embargo, desde mi punto de vista, contundentes ni definitivas para cuestionar la opción resocializadora en su conjunto; otra, el mayoritario alejamiento de las teorías retribucionistas, que ha provocado, como reacción, una más intensa fijación de los postulados preventivos-generales; tercera, la mayor fortaleza de la sociedad frente al individuo y la vocación de las diversas instituciones que 
desarrollan sistemas de control social por la prevalente protección de los interés sociales.

Todo lo expuesto al respecto se hace sobre la convicción de su excepcionalidad. La instrumentalización conjunta de una y otra, para conseguir los objetivos preventivos $y$, en consecuencia, la efectiva protección de bienes jurídicos es un fin irrenunciable, más en un sistema unificador preventivo, como el aquí defendido, que necesita de un cuidado equilibrio entre ambas para lograr ofrecer un verdadero fundamento teórico a la función de la pena, que difícilmente se ha de conseguir sino es con la adecuada articulación integradora de sus elementos más relevantes.

III.

No quisiera terminar este discurso, y les pido benevolencia con semejante abuso de la palabra, en contraprestación responsable me comprometo a ser telegráfico, sin hacer brevísima referencia a las alternativas a la pena, en concreto a la muy usada pena de prisión, siendo absolutamente consciente que un mínimo estudio de su concepto, naturaleza y alcance exigiría otra larga exposición por su complejidad y extensión, cuestión que, obviamente, no voy a hacer, al menos en este momento.

La imprescindible invocación a la búsqueda y encuentro de alternativas a la pena de prisión -pudiera parecer que planteada así en el contexto en el que estamos, se presenta como la contra argumentación de la función de la pena para la protección de bienes jurídicos, lo que indudablemente no es la realidad ya que es una forma exquisitamente válida y coherente de conseguir también esa función y esos objetivoses una constante temporal posiblemente con menos éxito, por ahora, pero no por ello menos importante, que el desarrollo de la que pretende sustituir. Es paradójico, pero al mismo tiempo real, que las reiteradas demandas, por ciertos sectores, otros están empecinados en su negación, de sustitutivos penales se oscurezcan una y otra vez con la prepotencia de una pena que, por necesaria, no cede prácticamente terreno. Nimio es afirmar que existen niveles distintos entre las diversas legislaciones en torno a tales alternativas, a su grado de aplicación y a su eficacia real, que no siempre coinciden con la descripción nominal de tales opciones en los Textos punitivos que, por lo general, atienden a su regulación, al menos desde una perspectiva formal. 
Son, presentadas, generalmente, en una doble dimensión. Por un lado, como alternativas derivadas de la propia naturaleza de las penas, en las que se integran con carácter general las penas privativas de derechos, la pena de multa y la de localización permanente, relacionadas por el artículo 33 de nuestro Código punitivo, que tienen como función básica, de todas las penas, la de protección de bienes jurídicos pero junto a ella, con los mecanismos preventivos señalados, asimismo una función alternativa a la pena de prisión a ensalzar, como mecanismo corrector del uso expansivo de ésta, en el Estado garantista; por otro, de alternativas específicas o sustitutivos penales en los que se acoge la suspensión de ejecución de las penas privativas de libertad, la sustitución y la libertad condicional, progresivamente bien tratadas por nuestro legislador.

En este sentido y en línea con los parámetros esenciales de Naciones Unidas al respecto es imprescindible apostar en los Ordenamientos jurídicos internos por las medidas no privativas de libertad para así proporcionar otras opciones, reducir la aplicación de las penas de prisión y racionalizar las políticas de justicia penal, teniendo en cuenta el respeto a los derechos humanos, las exigencias de justicia social y las necesidades de rehabilitación del delincuente. Junto a ello, y para ello, se precisa alcanzar un equilibrio adecuado entre los derechos de los delincuentes, los de las víctimas, el interés de la sociedad en la seguridad pública y la prevención del delito, sin menoscabo de la función esencial de protección y prevención de la pena.

La conveniente apuesta por una eficaz política criminal alternativa, fundamentalmente para las penas de prisión de corta y media duración, requiere como imprescindible una progresiva sensibilización de la comunidad social sobre la importancia y necesidad de dichas penas alternativas y de sustitutivos eficaces. Con ello, se ha de evitar lo que algún autor ha venido en denominar "miedo al cambio" de un sistema uniforme basado en la privación de libertad a otro diferenciador y pluriforme en sus respuestas, asentado en la trilogía: información-educación-sensibilidad. Esto quiere decir que asumiendo la necesidad de mantener dicha pena privativa de libertad, como pieza clave en los Ordenamientos penales actuales, ella ha de responder, cada vez más, a su naturaleza de ultima ratio de la ultima ratio del Derecho penal, con relevancia únicamente para las hipótesis de mayor gravedad y trascendencia social.

Cierto es, en aras a la objetividad valorativa, que, en este sentido, el Código penal español es prolijo, más que muchos otros Textos legales, en acoger alternativas a 
la pena de prisión, en las dos dimensiones antes explicitadas, pero también lo es que no deja de ser un cierto espejismo en cuanto el sistema de penas originariamente diseñado para el Código de 1995 y luego moldeado con inaudita frecuencia por las sucesivas reformas presenta como criterio en exceso preferente el uso de la pena de prisión, escoltado por un renovado catálogo de penas restrictivas de libertad y privativas de derechos que, en la mayoría de las ocasiones, son meras acompañantes de la primera. De nuevo una pretendida reforma, la contenida en el Anteproyecto 2012, se abona a estos criterios expansionistas. Otra oportunidad perdida.

IV.

La política punitiva, sobre la función aquí expuesta, de protección de bienes jurídicos a través de la prevención, tanto del Derecho penal como de la pena, con los matices introducidos, ha de ser objeto de un razonamiento y planificación sosegados por parte de los legisladores, para evitar, de esta manera, notorias discordancias entre unos grupos de delitos y otros, entre una reforma del Código penal y otra, entre el diseño teórico del Código y la realidad de su aplicación práctica. La existencia y necesidad del Derecho punitivo y de la pena, incluida, obviamente, la de prisión, es una opción incuestionable en la sociedad actual. Nada que objetar pragmáticamente al respecto, como no se ha hecho en este discurso. Lo que se ha planteado es la exigencia de un sistema de penas ágil y flexible que responda, en sus fines preventivos generales y especiales, sobre el sustento fundamentador de la culpabilidad y necesidad de pena, y de ésta como justificación, a los principios determinantes en el Estado social y democrático de Derecho, asumidos para su protección y al mismo tiempo como limitadores del ius puniendi estatal. Es necesario, en definitiva, lograr la confianza en la seriedad preventiva de la pena y la credibilidad del sistema punitivo respetuoso con los principios garantistas y humanitarios que su propia estructura demanda.

Tal ha sido el objetivo de esta exposición, mostrar, de la manera más breve posible, un modelo para el sistema de penas, unas convicciones conceptuales, una manera, posiblemente no exenta de ideología, de concebir el Derecho penal y su más importante consecuencia jurídica, la pena. Soy consciente que semejantes propuestas están abocadas al debate, que cualquier planteamiento dogmático es cuestionable, lo contrario dejaría a la dogmática sin especial sentido, pero también lo soy que la 
Revista Internacional de

Doctrina y Jurisprudencia

actividad intelectual exige crítica, confrontación de ideas y de objetivos ¡esa es su grandeza! 